\title{
Pengembangan Kewirausahaan di Fakultas Keguruan dan Ilmu Pendidikan Universitas Cokroaminoto Palopo
}

\section{Development of Entrepreneurship in Faculty of Teacher Training and Education Cokroaminoto Polopo}

\author{
${ }^{1}$ Ma'rufi, ${ }^{1}$ Muhammad Ilyas, ${ }^{1}$ Aswar Anas, ${ }^{2}$ Reski Yusrini Islamiayah \\ ${ }^{1}$ Program Studi Magister Pendidikan Matematika, Fakultas Keguruan dan Ilmu Pendidikan, \\ Universitas Cokroaminoto Palopo, Palopo \\ 2 Program Studi Pendidikan Bahasa Inggris, Fakultas Keguruan dan Ilmu Pendidikan, \\ Universitas Cokroaminoto Palopo, Palopo
}

Korespondensi: ma'rufi, marufi.ilyas@gmail.com

Naskah Diterima: 11 September 2019. Disetujui: 10 Februari 2020. Disetujui Publikasi: 11 Juni 2020

\begin{abstract}
Entrepreneurship among students is important to be developed and fostered from the start by providing entrepreneurial provisions to students while struggling so that students can develop entrepreneurship so that they can become strong entrepreneurs and successfully compete in the world. Various ways to motivate students to be interested in entrepreneurship have been done, but not yet optimal because of coaching that has not been integrated and sustainable. This fact underlies the importance of science and technology-based entrepreneurship development programs at the Faculty of Teacher Training and Education, University of Cokroaminoto Palopo. Faculty of Teacher Training and Education Entrepreneurship Development Program FKIP abbreviated method is a multi-year entrepreneurship program at University of Cokfroaminoo Palopo since 2018. The method used is the development of entrepreneurship based on training, mentoring, internships, and business consulting. The implementation team conducted PPK socialization to students before selecting tenants. Coaching activities that have been carried out are entrepreneurship training, assistance in preparing business plans, product packaging, marketing management, technology-based financial management, internships, and business consulting. The results of the implementation of the PPK FKIP Universitas Cokroaminoto Palopo have been carried out in accordance with the program and targets to be achieved. PPK FKIP is an entrepreneurial program with the dimension of innovation in business creation that synergizes the business world with the world of education using the Warung Pendidikan technique, abbreviated as Warpen. Over the past two years ten new entrepreneurs have been produced. The first year tenants are Accessories Warpen, Decoration Warpen, Tutoring Warpen, Data Analysis Warpen, and Design Warpen. Business fields in the second year, namely the Warpen Makeup, Miniature Warpen, Culinary Warpen, Gymnastics Warpen, and Translater Warpen.
\end{abstract}

Keywords: Development, entreprenurship, warpen, college students, alumny.

Abstrak. Kewirausahaan di kalangan mahasiswa penting untuk dikembangkan dan dibina sejak awal dengan memberi bekal kewirausahaan kepada mahasiswa sekaligus sebagai motivasi agar mahasiswa dapat mengembangkan kewirausahaan sehingga dapat menjadi pengusaha yang tangguh dan sukses menghadapi persaingan global. Berbagai cara untuk memotivasi mahasiswa agar tertarik untuk berwirausaha telah dilakukan, namun hasilnya belum optimal karena pembinaan yang belum terintegrasi dan berkelanjutan. Fakta tersebut melatarbelakangi pentingnya program pengembangan kewirausahaan berbasis ilmu pengetahuan dan teknologi di 
Fakultas Keguruan dan Ilmu Pendidikan Universitas Cokroaminoto Palopo. Program Pengembangan Kewirausahaan Fakultas Keguruan dan Ilmu Pendidikan Metode disingkat PPK FKIP merupakan program kewirausahaan multi tahun di Universitas Cokfroaminoo Palopo sejak tahun 2018. Metode yang digunakan pengembangan kewirausahaan yaitu pelatihan, pendampingan, magang, dan konsultasi bisnis. Tim pelaksana melakukan sosialisasi PPK kepada mahasiswa sebelum dilaksanakan seleksi tenant. Kegiatan pembinaan yang telah dilakukan yaitu pelatihan kewirausahaan, pendampingnan penyusunan business plan, pengemasan produk, manajemen pemasaran, pengelolaan keuangan berbasis teknologi, magang, dan konsultasi bisnis. Hasil pelaksanaan PPK FKIP Universitas Cokroaminoto Palopo sudah terlaksana sesuai denganprogram dan target yang ingin dicapai. PPK FKIP merupakan program kewirausahaan berdimensi inovasi kreasi bisnis yang mengsinergikan dunia usaha dengan dunia pendidikan menggunakan teknik Warung Pendidikan disingkat Warpen. Selama dua tahun telah dihasilkan sepuluh wirausaha baru. Bidang usaha tenant tahun pertama yaitu Warpen Aksesoris, Warpen Dekorasi, Warpen Bimbingan Belajar, Warpen Analisis Data, dan Warpen Desain. Bidang usaha pada tahun kedua yaitu Warpen Tata Rias, Warpen Miniatur, Warpen Kuliner, Warpen Senam, dan Warpen Translater.

Kata Kunci: Pengembangan, kewirausahaan, warpen, mahasiswa, alumni.

\section{Pendahuluan}

Kewirausahaan di perguruan tinggi penting untuk ditumbuhkembangkan agar para lulusan perguruan tinggi lebih menjadi pencipta lapangan kerja dari pada pencari kerja. Mahasiswa dibina sejak awal dengan memberi bekal kewirausahaan sekaligus sebagai motivasi agar mahasiswa dapat mengembangkan kewirausahaan sehingga dapat menjadi pengusaha yang tangguh dan sukses menghadapi persaingan global. Di bidang pendidikan pembinaan dan pertumbuhan dunia wirausaha di Indonesia masih perlu pembinaaan yang sistematis dan berkelanjutan.

Ada 3 faktor dominan dalam memotivasi sarjana menjadi wirausahawan yaitu faktor kesempatan, faktor kebebasan, dan faktor kepuasan hidup (Sutabri, 2008). Ketiga faktor itulah yang membuat mereka menjadi wirausahawan. Penelitian ini sangat membantu pihak perguruan tinggi dalam memberikan informasi kepada para mahasiswanya, bahwa menjadi wirausahawan akan mendapatkan beberapa kesempatan, kebebasan dan kepuasan hidup (Siswoyo, 2009).

Pada Agustus 2017 lalu, BPS mengungkapkan bahwa jumlah pengangguran naik menjadi 7,04 juta jiwa, dari yang sebelumnya hanya 7,03 juta jiwa di bulan Agustus 2016. Peningkatan ini namun diiringi dengan penurunan angka Tingkat Pengangguran terbuka atau TPT, dari 5,61\% menjadi 5,50\%. TPT sendiri merupakan persentase jumlah pengangguran yang termasuk dalam penduduk usia kerja terhadap jumlah angkatan kerja. Pada bulan Februari 2018, BPS melaporkan bahwa jumlah pengangguran di Indonesia berkurang sebanyak 140.000 jiwa. Persentase TPT yang juga turun ke angka 5,13\% dari 5,33\% pada Februari 2017. Total jumlah angkatan kerja tahun 2018 naik sebanyak 2,39 juta dari Februari 2017 menjadi 133,94 juta jiwa, dengan jumlah pengangguran sebanyak 6,87 juta dan yang bekerja sebanyak 127,07 juta jiwa. Data BPS tersebut menunjukkan bahwa terjadi penurunan pengangguran namun jumlah pengangguran di Indonesia masih sangat tinggi.

Pendidikan kewirausahaan di perguruan tinggi diharapkan bisa menyiapkan mahasiswa untuk berani mandiri, tidak lagi terfokus menjadi pencari kerja. Apalagi data pengangguran terdidik di Indonesia menunjukkan, semakin tinggi pendidikan seseorang, semakin rendah kemandirian dan semangat kewirausahaannya. Beberapa penelitian sebelumnya menyebutkan bahwa keinginan berwirausaha para mahasiswa merupakan sumber bagi lahirnya wirausaha-wirausaha masa depan (Gorman et al., 1997; Kourilsky \& Walstad, 1998). Sikap, perilaku, dan pengetahuan mereka tentang kewirausahaan akan membentuk kecenderungan mereka untuk membuka usaha-usaha baru di masa mendatang (Indarti \& Rostiana, 2008). 
Universitas Cokroaminoto Palopo (UNCP) membina empat fakultas yaitu Fakultas Keguruan dan Ilmu Pendidikan (FKIP), Fakultas SAINS, Fakultas Teknik Informatika, dan Fakultas Pertanian. Fakultas yang terbesar adalah FKIP yang mengelola 6 program studi untuk program sarjana dengan jumlah mahasiswa 2500 orang atau hampir 50\% dari seluruh mahasiswa UNCP. Mahasiswa FKIP juga berhasil menembus Pekan Ilmiah Mahasiswa Nasional ke 29 di Bogor dan ke 32 di Universitas Udayana Bali.

Ciri khas utama program kewirausahaan di FKIP adalah kewirausahaan yang berbasis pendidikan. Secara garis besar jenis usaha dari tenant PPK-FKIP dibagi menjadi dua jenis wirausaha yang di rintis yaitu wirausaha jasa dan wirausaha produk. Wirausaha jasa seperti wirausaha jasa analisis dan interpretasi data penelitian, bimbingan belajar, desain, instruktur senam. Sedangkan untuk wirausaha produk seperti assesoris wisuda, miniatur, dan olahan makanan ringan berbasis kearifan lokal. Jasa dan produk tersebut memiliki potensi bisnis yang sangat menarik apabila dikembangkan khususnya untuk pendidikan. Produk kewirausahaan mahasiswa FKIP UNCP sangat potensial dan memiliki nilai jual yang cukup tinggi, disamping memiliki keunikan serta memiliki nilai artistik karena tetap menampilkan nilai-nilai lokal filosofi Sulawesi Selatan dengan penampilan yang lebih menarik dan modern. Dengan demikian usaha rintisan mahasiswa tersebut layak untuk dikembangkan sebagai wirausaha mandiri dan berkembang.

Berdasarkan uraian di atas dan observasi yang dilakukan maka masalah pengangguran menjadi masalah yang sangat serius, sebagian lulusan perguruan tinggi termasuk di UNCP lebih siap sebagai pencari kerja daripada berwirausaha. Minat mahasiswa dan lulusan perguruan tinggi masih rendah hal ini disebabkan tantangan yang dihadapi dan bekal untuk berwirausa yang masih kurang didapatkan di perguruan tinggi. Pengetahuan yang masih kurang tersebut terlihat pada hasil observasi yang menunjukkan bahwa mahasiswa belum matang dalam pembukuan yang rancu sehingga arus kas belum terorganisir dengan baik. Maka fakta tersebut mendorong agar terselenggaranya program pengembangan kewirausahaan di Universitas Cokroaminoto Palopo, khususnya di Fakultas Keguruan dan Ilmu Pendidikan. Tujuan program pengembangan kewirausahaan Fakultas Keguruan dan Ilmu Pendidikan adalah menghasilkan wirausaha baru yang mandiri berbasis iptek, melalui program yang terintegrasi dengan melibatkan dosen, narasumber, mahasiswa, dan alumni.

\section{Metode Pelaksanaan}

Tempat dan Waktu. Program Pengembangan Kewirausahaan Fakultas Keguruan dan Ilmu pendidikan Universitas Cokroaminoto Palopo dipusatkan di Kampus I UNCP, Jalan Latamacelling Nomor 19 Kota Palopo Sulawesi Selatan. PPK FKIP merupakan program kewirausahaaan multi tahun yang dilaksanakan sejak tahun 2018 dan tahun 2019 ini merupakan tahun kedua dari PPK di FKIP. Waktu pelaksanaan mulai bulan Februari sampai dengan bulan November 2019.

Khalayak Sasaran. Sasaran dari Program PPK adalah mahasiswa FKIP, diutamakan yang melakukan kegiatan PKM Kewirausahaan dan alumni FKIP yang sedang menjalankan usaha. Program studi di FKIP yaitu: Pendidikan Matematika, Pendidikan Bahasa Inggris, Pendidikan Bahasa Indonesia, Pendidikan Pancasila dan kewarganegaraan, Pendidikan Bilogi, serta Pendidikan Guru Sekolah Dasar. Untuk meningkatkan keefektifan program PPK di Fakultas Keguruan dan Ilmu Pendidikan, pengelola juga melibatkan beberapa dosen yamg bukan tim pelaksana dari FKIP maupun dari Fakultas Pertanian, Fakultas Sains, dan Fakultas Teknik Komputer serta tenaga ahli dari luar UNCP terkait dengan kebutuhan tenant PPK. Jumlah tenat PPK-FKIP UNCP Tahun 2018 dan 2019 yaitu 20 mahasiswa. 
Metode Pengabdian. Metode pengabdian yang dilakukan pada PPK FKIP ini yaitu (1) sosialisasi program PPK, (2) seleksi tenant, (3) pelatihan, pendampingan dan magang, dan (4) konsultasi bisnis. Sosialisasi dilakukan melalui pertemuan secara klasikal dengan memberikan penjelasan secara umum tentang program PPK. Proses seleksi tenant PPK FKIP dilaksanakan oleh tim pelaksana PPK dengan memperhatikan persyaratan yang harus dipenuhi oleh tenant. Metode yang digunakan dalam pelatihan ini melalui tatap muka, dimana narasumber menjelaskan tentang mengembangkan semangat berwirausaha, membangun pendidikan berbasis kewirausahaan, pengembangan ide usaha, strategi menangkap peluang usaha, penyusuann rencana usaha, pemahaman resiko usaha, strategi mencapai keunggulan bersaing, pengelolaan usaha dan strategi kewirausahaan, teknik pengembangan usaha. Metode yang digunakan dalam pendampingan adalah demonstrasi dan praktik manajemen pemasaran, pengelolaan keuangan, pengemassan produk. Kunjungan dan konsultasi disesuaikan dengan kebutuhan tenant. Kegiatan ini terbagi dalam beberapa komponen seperti kegiatan produksi, promosi dan pemasaran, serta sistem akuntansi keuangan. Konsultasi berkaitan erat dengan permasalahan yang dihadapi oleh tenant untuk membantu memcahkan persoalan tersebut.

Indikator Keberhasilan. PPK merupakan layanan kewirausahaan di perguruan tinggi dengan prinsip professional, mandiri, dan berkelanjutan, serta berwawasan ekonomi berbasis pengetahuan. Indikator keberhasilan program PPK yaitu: (1) adanya pengembangan dan peningkatan pengetahuan keterampilan tenant dalam membuka binsis (berwirausaha), (2) menciptakan 5 wirausaha baru yang mandiri dan berdaya saing berbasis Ipteks, (3) menyelenggarakan pendampingan dan pelatihan kewirausahaan yang disesuaikan dengan kebutuhan tenant, (4) mempublikasikan laporan program melalui media cetak dan online serta melalui seminar dan jurnal yang bereputasi.

Metode Evaluasi. Metode evaluasi yang digunakan adalah pemberian kuesionar kepada tenant dan observasi terkait kondisi usaha tenant sebelum dan setelah menjadi tenant PPK. Aspek kinerja yang dievaluasi yaitu motivasi berwirausaha, kelembagaan dan sumber daya manusia, kemampuan teknis/produksi, pengembangan usaha, manajemen pemasaran, pengelolaan keuangan, dan dana yang dikelola. Evaluasi kinerja bisnis tenant dalam program PPK FKIP UNCP penting untuk dilakukan sebagai bahan dalam penyusunan peta bisnis tenant, apa sudah sesuai dengan perencanaan, pelaksanaan, penilaian kegiatan bisnis dapat memenuhi target. Hasil evaluasi dijadikan sebagai acuan dalam menentukan kegiatan pendampingan bagi tenant.

\section{Hasil dan Pembahasan}

\section{A. Sosialisasi Program PPK-FKIP UNCP}

Pelaksanaan sosialisasi program PPK-FKIP UNCP dilakukan dengan menyebarkan informasi kepada mahasiswa khusunya FKIP bahwa FKIP melalui PPK-FKIP memberikan kesempatan kepada mahasiswa dan alumni yang memiliki motivasi untuk berwirausaha maupun kepada mahasiswa dan alumni yang sedang merintis usaha untuk mendapatkan pendampingan untuk menjadi wirausahawan mandiri, handal, dan berdaya saing, melalui program ini. Program ini juga dihusukan bagi mahasiswa yang memperoleh program PKM Kewirasuhaan dari Dikti, dan wirausaha dari sumber lain. Penyebaran informasi program PPK-FKIP UNCP ini dilaksanakan melalui penyebaran brosur pada papan pengumuman di lingkup FKIP dan melalui alumni.

\section{B. Seleksi Tenant PPK-FKIP UNCP}

Pelaksanaan Program PPK di Fakultas Keguruan dan Ilmu Pendidikan Universitas Cokroaminoto Palopo adalah tenant yang dibina diambil dari 
mahasiswa FKIP yang melakukan kegiatan PKM Kewirausahaan dan kegiatan kewirausahaan lainnya, serta alumni FKIP yang sedang menjalankan usaha. Ada beberapa pola pendekatan yang dilakukan dengan langkah-langkah kongkrit sebagai berikut:

a. Membuka posko pendaftaran tenant sebagai peserta setelah dilaksanakan sosialisasi secara terbuka di FKIP

Adapun syarat rekruitmen tenant adalah;

1) Mahasiswa yang memperoleh program PKM Kewirasuhaan dari Dikti, wirausaha dari sumber lain, serta alumni yang sedang menjalankan usaha.

2) Memiliki motivasi dan dedikasi tinggi untuk mengembangkan wirausahanya

3) Mempunyai komitmen untuk mengikuti program PPK

4) Berstatus sebagai mahasiswa aktif atau alumni dan sedang menggeluti dunia wirausaha

Prosedur pendaftaran sebagai tenant:

1) Mengambil formulir secara langsung di secretariat PPK FKIP

2) Calon peserta program PPK FKIP mengisi semua muatan pada formulir

3) Melampirkan persyaratan yang diwajibkan seperti CV, Kartu Mahasiswa, dan lain-lain

4) Mencantumkan deskripsi usaha yang sedang dijalankan secara tertulis

5) Formulir yang telah diisi dan lengkap beserta lampirannya dikembalikan ke sekretariat PPK FKIP

b. Proses seleksi peserta PPK FKIP

Proses seleksi peserta PPK FKIP dilaksanakan oleh pengelola dengan berpedoman kriteria yang telah ditetapkan. Selain itu tenaga konsultan atau narasumber yang dijadikan partner program juga dilakukan seleksi berdasarkan kepakaran dan kebutuhan dari tenant yang telah direkrut sebelumnya. Rincian calon tenant merintis usaha dan wirausaha baru program PPK FKIP UNCP tahun 2018 dan 2019 sebagaimana terdaftar dalam tabel berikut ini:

Tabel 1. Daftar tenant PPK FKIP UNCP Tahun 2018 dan 2019

\begin{tabular}{cllll}
\hline No & Tenant & Program & Usaha & Kategori \\
\hline 1 & Jusriati & Wirausaha Baru 2019 & $\begin{array}{l}\text { Malebby Make } \\
\text { Up }\end{array}$ & $\begin{array}{l}\text { Warpen Tata } \\
\text { Rias }\end{array}$ \\
2 & Anita Anas & Wirausaha Baru 2019 & $\begin{array}{l}\text { Kuliner Palopo } \\
\text { Warpen Tata } \\
\text { Rias }\end{array}$ & $\begin{array}{l}\text { Warpen } \\
\text { Senam }\end{array}$ \\
3 & Hijrawati & Wirausaha Baru 2019 & Hi5 Sport & $\begin{array}{l}\text { Warpen } \\
\text { Miniatur }\end{array}$ \\
4 & Iswan & Wirausaha Baru 2019 & Miniatur Palopo & Warpen \\
5 & Mustafa Mustain & Wirausaha Baru 2019 & Café baca & $\begin{array}{l}\text { Literasi } \\
\text { Warpen }\end{array}$ \\
6 & NurAgustina & Wirausaha Baru 2019 & SuKaBeLi T/B & $\begin{array}{l}\text { Tekstil } \\
\text { Warpen }\end{array}$ \\
7 & Hikmah & Merintis Usaha & Jasa Translate & Translater \\
8 & Indah & Merintis Usaha & Jasa Translate & Warpen \\
& & Translater \\
9 & Surya Pratiwi & Merintis Usaha & Busana & Warpen \\
& & Muslimah & Muslimah \\
10 & Trilana & Merintis Usaha & Privat & Warpen \\
& & Pintar \\
11 & Herman & Merintis Usaha & Percetakan & Warpen Press
\end{tabular}




\begin{tabular}{|c|c|c|c|c|}
\hline 12 & Karpianti & Merintis Usaha & Tanaman Hias & $\begin{array}{l}\text { Warpen } \\
\text { Tanaman } \\
\text { Hias }\end{array}$ \\
\hline 13 & Nirwana & Merintis Usaha & $\begin{array}{l}\text { Instruktur } \\
\text { Senam }\end{array}$ & $\begin{array}{l}\text { Warpen } \\
\text { Senam }\end{array}$ \\
\hline 14 & Asri Ainun & Merintis Usaha & $\begin{array}{l}\text { Instruktur } \\
\text { Senam }\end{array}$ & $\begin{array}{l}\text { Warpen } \\
\text { Senam }\end{array}$ \\
\hline 15 & $\begin{array}{l}\text { Andi Mayang } \\
\text { Sari }\end{array}$ & Merintis Usaha & Kuliner & $\begin{array}{l}\text { Warpen } \\
\text { Kuliner }\end{array}$ \\
\hline 16 & Zara Liku Rarak & Merintis Usaha & Tata Rias & $\begin{array}{l}\text { Warpen Tata } \\
\text { Rias }\end{array}$ \\
\hline 17 & $\begin{array}{l}\text { Tri Nur } \\
\text { handayani }\end{array}$ & Merintis Usaha & Privat & $\begin{array}{l}\text { Warpen } \\
\text { Pintar }\end{array}$ \\
\hline 18 & Hasma & Merintis Usaha & Sablon & $\begin{array}{l}\text { Warpen } \\
\text { Sanik }\end{array}$ \\
\hline 19 & Puspa & Merintis Usaha & Anyaman & $\begin{array}{l}\text { Warpen } \\
\text { Antik }\end{array}$ \\
\hline 20 & Ummul Khair & Merintis Usaha & Anyaman & $\begin{array}{l}\text { Warpen } \\
\text { Antik }\end{array}$ \\
\hline
\end{tabular}

\section{Pelatihan, pendampingan dan magang Program PPK-FKIP UNCP}

Kegiatan pelatihan, pendampingan, dan magang program PPK-FKIP UNCP dijelaskan sebagai berikut:

\section{Pendampingan}

Kegiatan pendampingan bertujuan memberikan pengetahuan kewirausahaan dan system manajemen bisnis yang moderen dan berdaya saing disamping program magang untuk menambah keterampilan berwirausaha bagi tenant yang dibina nantinya. Pola pembimbingan yang diterapkan pada pelayanan dan pendampingan wirausaha pada program PPK FKIP UNCP telah disusun secara terstruktur dsn berkesinambungan dengan metode coaching NLP (Neuro Linguistic Program). Dalam metode ini akan mengidentifikasikan kondisi awal usaha peserta dengan membagi masalah usaha tenant menjadi lima masalah yang lebih spesifik yaitu profil usaha, profil produk, pemasaran, pembukuan, bisnis plan teknik pengembangan usaha, resiko usaha, strategi mencapai keunggulan bersaing. Metode ini dilakukan dengan cara melakukan Focus Group Discussion (FGD) antara tenant, dosen pengampu mata kuliah kewirausahaan dan praktisi serta berupaya menggali kekuatan sumber daya internal dan eksternal tenant masing-masing.

Kegiatan pendampingan yang telah dilakukan yaitu (1) pendampingan penyusunan business plan, (2) pendampingan pengemasan produk berbasis teknologi, (3) pendampingan manajemen pemasaran berbasis online, (4) pendampingan pengelolaan keuangan dengan menggunakan aplikasi Ipos4

1) Pendampingan Penyusunan Business Plan

Pendampingan penyusunan Business Plan bagi tenan PPK FKIP UNCP dilaksanakan pada Hari Sabtu, Tanggal 20 April 2019 di Kampus I UNCP (Gambar 1). Honig (2004) menyatakan bahwa Business Plan merupakan salah satu aspek perencanaan pra-startup. Business Plan didefinisikan sebagai dokumen tertulis yang menggambarkan keadaan saat ini dan perkiraan masa depan suatu usaha.

Hasil kegiatan pendampingan penyusunan Business Plan secara umum di bagi menjadi 2 yaitu pemberian materi dan Praktek penyusunan Business Plan. Pemberian materi berupa pentingnya perencanaan bisnis yang baik dan bisnis model Canvas. Pemberian materi tersebut dimaksudkan agar para tenan PPK FKIP mampu mengetahui dasar bagaimana membuat Business Plan yang baik. Yang nantinya dapat diimplementasikan terhadap bisnis yang dimiliki. Mulai dari tenan 
mengetahui costumer segment yang dimiliki, velue prepositions, channels, costumer relationship, revenue streams, key partnerships, key activities, key resources, dan cost structure.

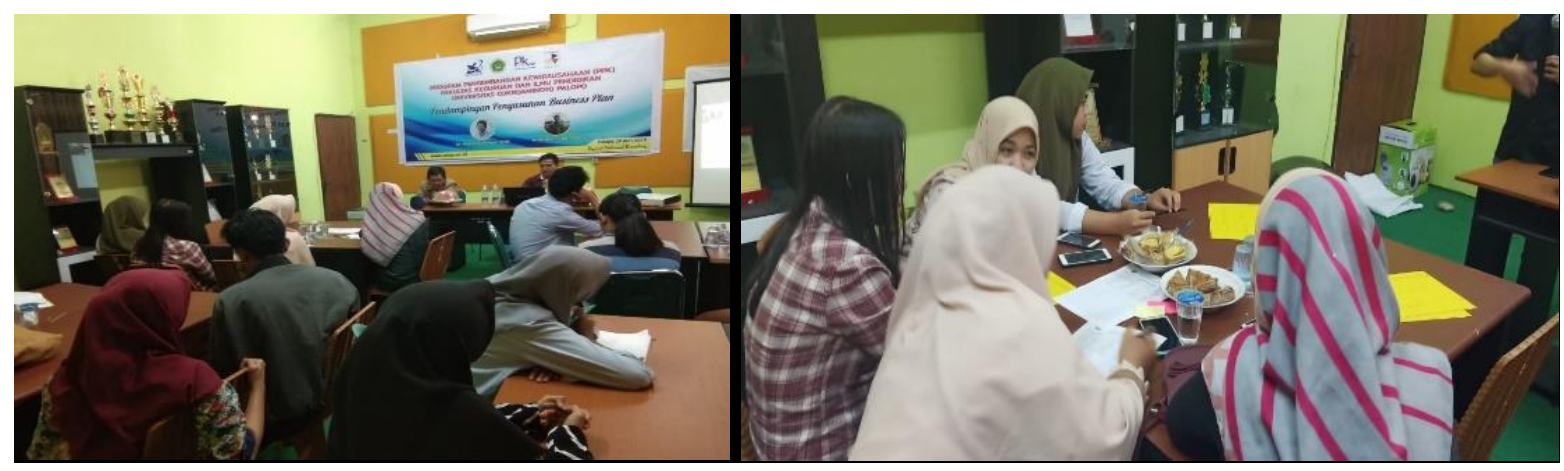

Gambar 1. Pendampingan business plan

2) Pendampingan Pengemasan Produk

Pemilihan kemasan produk merupakan hal terpenting dan harus diutamakan. Pemilihan kemasan yang akan digunakan, agar memperhatikan produk terlebih dahulu dalam memilih kemasan yang cocok sehingga kemasan yang sesuai dengan produk yang dimiliki sehingga dapat menjadi icon yang bisa membuat pelanggan selalu ingat dengan produk yang dijual. Kemasan yang dipilih disesuaikan dengan ukuran produk. Suasana pendampingan nampak dalam gambar berikut.
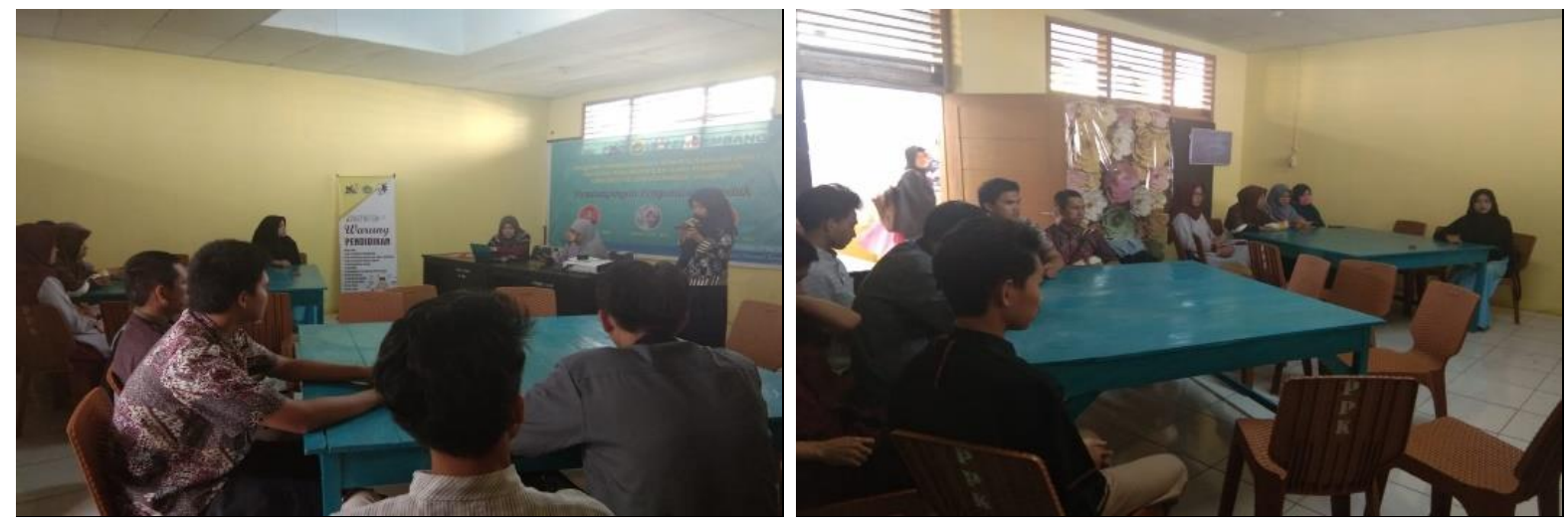

Gambar 2. Pendampingan pengemasan produk

Wells, et al. (2007) menyatakan bahwa kemasan sebagai identitas produk, pentingnya kemasan sebagai kekuatan alat komunikasi secara langsung. Dalam dunia kompetitif bagian pengemasan harus bekerja lebih keras jika ingin mendapatkan perhatian konsumen.

3) Pendampingan Manajemen Pemasaran

Pendampingan manajemen pemasaran dilaksanakan pada tanggal 30 Juni 2019 di Kampus I UNCP Kota Palopo (Gambar 3). Kegiatan pendampingan ini memberikan pemahaman dan keterampilan manajerial dalam menjalankan usaha, mempercepat proses belajar sehingga dapat menyelesaikan persoalaan operasional usaha, dan meningkatkan kinerja usaha secara efisien. Selain itu pendampingan ini juga meningkatkan semangat dan motivasi tenant. Pada kegiatan ini alternatif teknologi yang diterapkan adalah memperkenalkan praktik-praktik manajerial.

Hills, et al. (2008) menyatakan interprestasi kewirausahaan dalam pemasaran meliputi Orientasi konsumen versus "orientasi inovasi". Manajer dan pemilik usaha berpendapat bahwa perubahan lebih sering dipicu oleh eksistensi ide baru atau tekanan kompetitif, bukan kebutuhan konsumen yang dapat diketahui dengan pasti. Bisnis awal tidak melalui analisis pasar tetapi melalui perasaan intuitif 
tentang sesuatu yang harus dibutuhkan. Kreativitas dan inovasi dalam pengembangan produk atau jasa adalah kegiatan pemasaran dari entrepreneurship yang sukses dan tidak melalui kegiatan penelitian yang hati-hati tentang kebutuhan konsumen.

Komunikasi berita dari mulut ke mulut di antara wirausaha dan pemilik usaha kecil menjadi sumber utama dari ide inovatif. Pemasaran melalui berita dari mulut ke mulut merupakan hal yang penting dalam proses inovatif karena hal ini memainkan peran penting dalam penggunaan produk dan jasa baru dari konsumen. Komunikasi personal informal adalah sebuah aspek pemasaran kewirausahaan (Hadiyati, 2010).

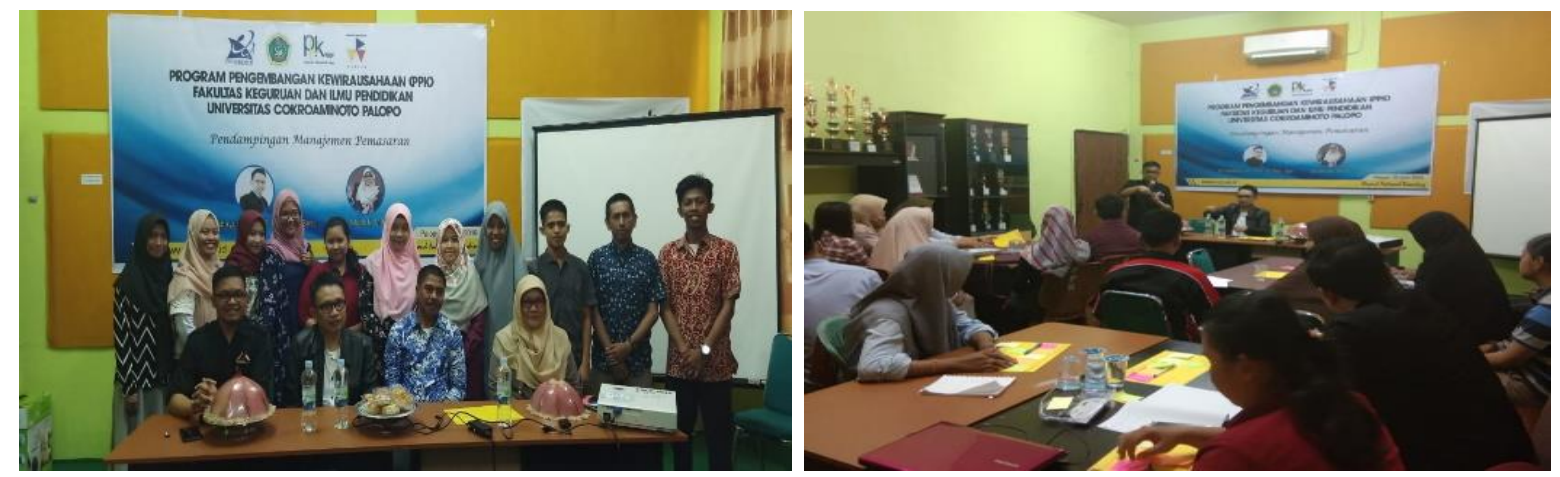

Gambar 3. Pendampingan manajemen pemasaran

4) Pendampingan Pengelolaan Keuangan Berbasis Teknologi

Pendampingan pengelolaan keuangan berbasis teknologi dilaksanakan pada tanggal 20 Juli 2019 di Aula Gedung E Kampus I UNCP (Gambar 4). Hasil kegiatan pendampingan ini juga memberikan pemahaman tentang pengelolaan keuangan dengan menggunakan software ipos 4. Software ini mampu mengecek stok barang yang dimiliki oleh para tenant dalam usahanya sehingga nantinya dapat memudahkan para tenant dalam mengetahui stok barang yang masih tersedia serta mampu mengingatkan para tenant apabila stok barang yang dimiliki sudah hampir habis. Selain itu, software ipos 4 ini juga dapat membuat dan mencetak atau menscan barcode yang biasanya digunakan di minimarket.
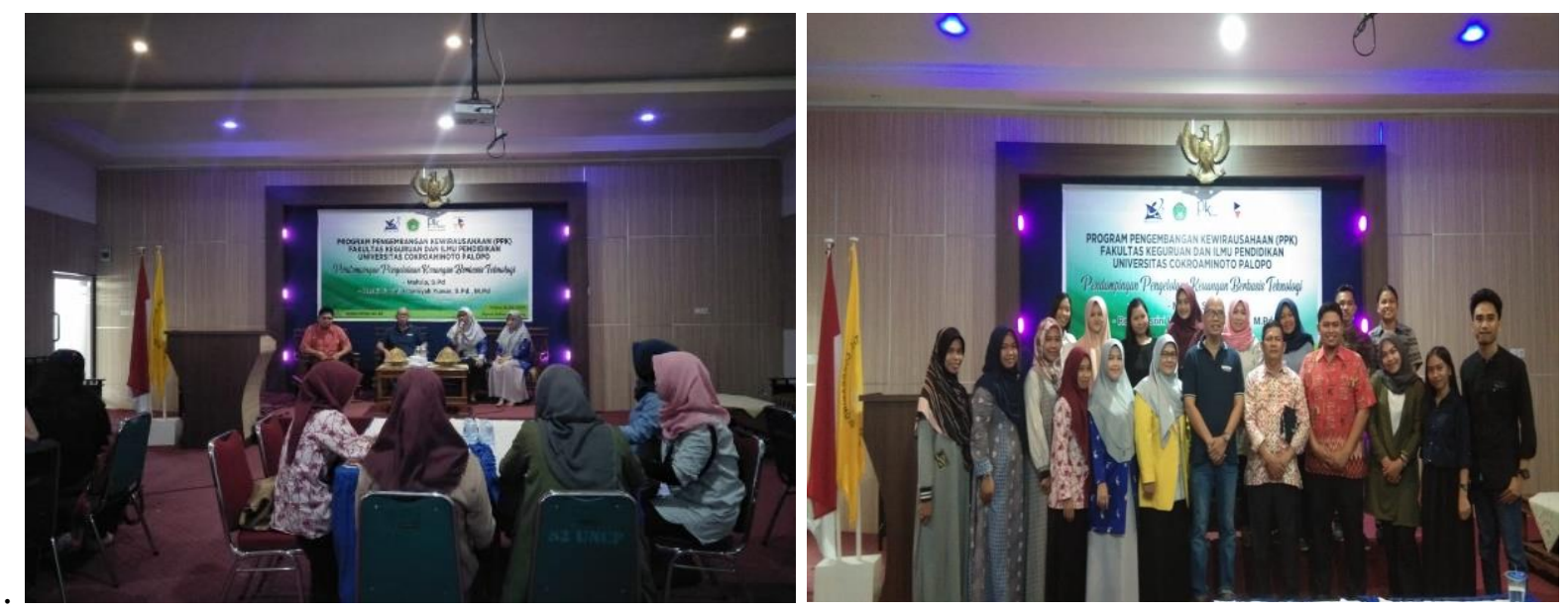

Gambar 4 Pendampingan Pengelolaan Keuangan

Literasi keuangan merupakan tingkat pengetahuan dan kemampuan untuk mengelola keuangan. Beberapa studi terdahulu mengemukakan bahwa literasi keuangan berperan penting bagi business sustainability. Tingkat pengetahuan dan kemampuan pengelolaan keuangan yang dimiliki pelaku usaha menjadi salah satu 
kunci sukses bagi keberlangsungan usahanya. Hasil penelitian mengungkapkan bahwa dengan memiliki literasi keuangan yang baik maka pelaku usaha akan cenderung mampu membuat keputusan bisnis yang berorientasi jangka panjang. Selain itu, pelaku usaha akan cenderung mampu membuat konsep aktivitas bisnis yang berkelanjutan sehingga business sustainability-nya tetap dapat dipertahankan (Puspitaningtyas, 2017).

\section{Pelatihan}

Tujuan Pelatihan adalah untuk memberikan pengetahuan dan pemahaman tentang kewirausahaan, memotivasi mahasiswa untuk berwirausaha, meningkatkan pemahaman manajemen organisasi, produksi, keuangan, dan pemasaran, memberikan pengetahuan dan pemahaman tentang rencana bisnis atau studi kelayakan usaha. Kegiatan pelatihan kewirausahaan dilaksanakan pada tanggal 2 Agustus 2019 di Unit Pengembangan Kewirausahaan dan Bisnis (UPKB) Universitas Hasanuddin Gambar 5).
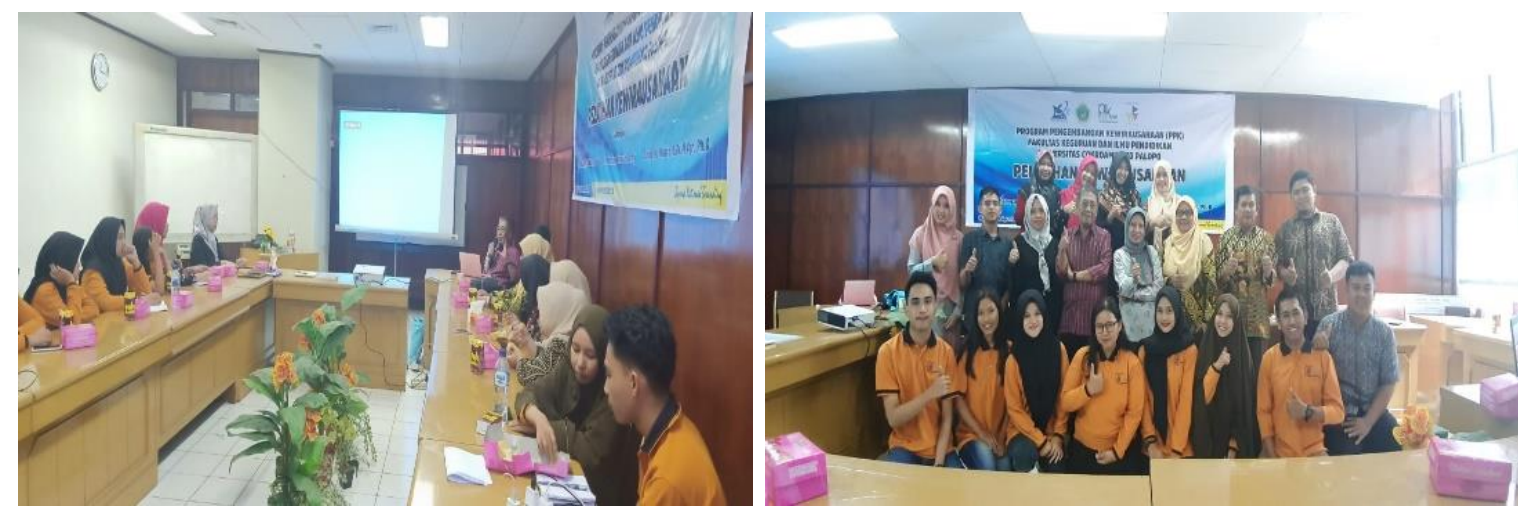

Gambar 5 Pelatihan Manajemen Kewirausahaan

\section{Magang}

Sampai saat ini Universitas Cokroaminoto Palopo belum memiliki PPUPIK sehingga untuk program pemagangan tenant PPK di Fakultas Keguruan dan Ilmu Pendidikan dilaksanakan kerjasama dengan beberapa UKM yang memiliki usaha sesuai dengan yang dijalankan oleh tenant.

\section{Konsultasi Bisnis}

Konsultasi disesuaikan dengan kebutuhan tenant. Kegiatan ini terbagi beberapa komponen seperti kegiatan produksi, promosi dan pemasaran, serta sistem akuntansi keuangan. Konsultasi berkaitan erat dengan permasalahan yang dihadapi oleh tenant untuk membantu memcahkan persoalan tersebut. Kunjungan dan konsultasi akan dilaksanakan oleh tim PPK, staf dosen, konsultan dan mitra, serta pihak-pihak yang berperan penting dalam program PPK.

Untuk mengoptimalkan program PPK di FKIP, lembaga ini juga merekrut beberapa dosen yang memiliki keterkaitan dengan program PPK yang dilaksanakan yang disesuaikan dengan kompetensi yang dimiliki, serta dalam pelaksanaannya dilakukan dengan koordinasi dengan pimpinan agar dosen tersebut diberikan ijin untuk ikut melaksanakan kegiatan PPK, misalnya kegiatan pembimbingan dan konsultasi usaha dan kerja, serta pengembangan kompetensi tenant menjadi mandiri.

Fakultas Keguruan dan Ilmu Pendidikan memiliki beberapa ruangan seminar dan ruangan khusus PPK-FKIP. UNCP juga memiliki Guest House, lembaga penerbitan dan percetakan yang dapat dimanfaatkan oleh tenant, kebun percobaan, pusat pembenihan, tambak ikan bandeng, nilai, dan lele. Semua fasilitas layanan tersebut dapat dimanfaatkan untuk layanan konsultasi kewirausahaan bagi tenant. 


\section{E. Keberhasilan PPK-FKIP UNCP}

Program kewirausahaan Fakultas Keguruan dan Ilmu Pendidikan berdimensi inovasi kreasi bisnis yang mengsinergikan dunia usaha dengan dunia pendidikan menggunakan teknik Warung Pendidikan disingkat Warpen. PPK FKIP telah menghasilkan 10 tenant wirausaha baru dengan bidang usaha yaitu: warpen aksesoris, warpen dekorasi, warpen bimbingan belajar, warpen analisis data, dan warpen desain, warpen tata rias, warpen miniature, warpen kuliner, warpen translater dan warpen senam.

Warpen Asesoris "Karni Asesoris" merupakan usaha yang bergerak dalam bidang penjualan asesoris mulai dari asesoris pendukung penampilan ataupun asesoris persiapan wisuda (boneka wisuda, buket bunga, selempang yudisium/wisuda). Asesoris yang dijual disesuaikan dengan keinginan pasar tergantung perkembangan fashion dan perkembangan seremonial yudisium dan wisuda. Sasaran pelanggan dalam usaha ini adalah masyarakat yang membutuhkan dukungan asesoris dalam fashionnya dan calon yudisium dan wisudawan yang membutuhkan asesoris (boneka wisuda, buket bunga, selempang yudisium/wisuda)

Warpen Dekorasi "Rumah Cantika" merupakan usaha yang bergerak dalam bidang dekorasi bunga-bunga cantik yang terbuat dari media kertas (Kertas jasmine/ kertas bufallo/ kertas padi) yang biasa digunakan sebagai backdrop untuk acara lamaran, wedding, ulang tahun, lahiran, baby shower, bridal shower dan acara lainya. Sasaran pelanggan dari usaha paper flower ini adalah masyarkat yang akan mengadakan pesta dan membutuhkan dekorasi-dekorasi cantik dari paper flower.

Warpen Bimbel "Soekma Education" merupakan usaha yang bergerak dalam bidang jasa pelayanan pendidikan yang melayani bimbingan belajar privat mandiri dan privat kelompok. Bimbingan dilakukan dengan mendatangi rumah pelanggan sesuai dengan kesepakatan jadwal. Adapun materi dalam bimbingan privat ini terfokus pada materi Matematika, Fisika (SMP, SMA), Matematika, IPA, IPS (SD). Sasaran pasar dari soekma education adalah siswa SD, SMP dan SMA dalam lingkup kota palopo yang membutuhkan bimbingan secara privat menganai materimateri tertentu yang dianggap susah di sekolah ataupun siswa yang ingin mengikuti suatu lomba seperti olimpiade dll.

Warpen Analisis Data "Rumah Data" Merupakan usaha yang bergerak dalam bidang analisis data, konsultasi statistik, serta pelatihan atau privat olah data. Rumah data bisa melakukan pembimbigan atau pengerjaan olah data secara tatap muka maupun online atau via telpon/WA. Sasaran pelanggan adalah mahasiswa tingkat akhir semua jurusan yang menggunakan analisis spss dalam penelitian.

Warpen Desain "Gea Design" merupakan usaha yang bergerak dalam bidang desain yang menyampaikan pesan dan informasi kepada massa dengan menggunakan cara sentuhan visual. Sasaran pasar dari gea design adalah masyarakat yang membutuhkan jasa desain dalam bentuk cover buku, brosur menarik, spanduk/baliho/backdrop, logo usaha, stempel, poster, kartu nama, dan berbagai desain lain.

Warpen Tata Rias "Malebby Make Up" merupakan bisnis yang bergerak pada bidang jasa tata rias wajah. Bisnis tata rias semakin cerah ditunjukkan dengan semakin meningkatnya permintaan jasa rias wajah. Keunggulan warpen tata rias ini adalah pelannggan bisa memesan via whatsup atau telepon. Pelayanan dapat dilakukan di rumah pelanggan atau di salon tata rias.

Warpen Miniatur "Ispusag Art" merupakan jenis usaha yang membuat duplikat suatu obyek yang ukurannya dikecilkan dari ukuran yang sebenarnya. Keunggulan dari warpen miniatur adalah menyediakan miniatur khas Sulawesi Selatan, Kota Palopo, dan Universitas Cokroaminoto Palopo. Miniatur yang 
disediakan oleh tenant antara lain miniatur perahu pinisi, istana datu Luwu, miniatur UNCP, dan miniatur lainnya.

Warpen Kuliner dengan usaha "Banana MZ, Krusa, dan Sampukala" merupakan salah satu jenis usaha yang selalu dibutuhkan dan tidak akan pernah mati karena makanan adalah kebutuhan pokok manusia yang paling utama. Banana MZ memasarkan 15 jenis olahan pisang, Krusa merupakan keripik dengan bahan dasar sagu, sedangkan sampukala merupakan jus dengan bahan dasar pattikala. Keunggulan produk warpen kuliner adalah produknya merupakan olahan pangan lokal.

Warpen Senam "Hi5 Sport" merupakan salah satu usaha yang bergeraka pada bidang olah raga. Senam merupakan jenis olah raga yang mempunyai beragam variasi dan manfaat, baik bagi fisik, maupun mental dan sosial. Senam yang dikembangkan antara lain senam kebugaran, jantung sehat dan senam tobelo. Keunggulan dari warpen senam ini adalah memadukan olah raga dan pemeriksaan kesehatan.

Warpen Literasi "Café Baca" merupakan usaha yang mengintergrasikan penyediaan buku-buku bacaan, akses internet dan menyediakan berbagai jenis jajanan sehingga pengunjung membaca mengakses internet dan menikmati hidangan yang disiapkan. Sasarannya adalah siswa, mahasiswa, dan masyarakat umum.

Kelembagaan PPK FKIP telah terbentuk dan menjalankan program sesuai dengan yang direncanakan serta mendapat dukungan moriil dan materil dari pimpinan Universitas Cokroaminoto Palopo. PPK FKIP membina 20 tenant setiap tahun yang terdiri dari $70 \%$ mahasiswa dan 30\% alumni yang sedang menjalankan usaha. Wirausaha baru yang dihasilkan setiap tahun rata-rata 5 tenant dengan usaha yang memiliki potensi bisnis dan keunggulan setiap warpen. Bidang usaha tenant selama dua tahun yaitu warpen aksesoris, warpen dekorasi, warpen bimbingan belajar, warpen analisis data, dan warpen desain, warpen tata rias, warpen miniatur, warpen kuliner, warpen literasi dan warpen senam.

Hasil ini sesuai dengan pengabdian Rifa’i, dkk., (2018), dan Adhawati, dkk., (2019) yang melibatkan mahasiswa dalam kegiatan pengembangan usaha menunjukkan bahwa mahasiswa mempunyai kemampuan sebagai wirausaha.

\section{Kesimpulan}

PPK FKIP UNCP merupakan program kewirausahaan berdimensi inovasi kreasi bisnis yang mengsinergikan dunia usaha dengan dunia pendidikan menggunakan teknik Warung Pendidikan disingkat Warpen. Pelaksanaan Program PPK-FKIP UNCP terdiri dari sosialisasi, selesksi tenant, pelatihan, pendampingan dan magang serta konsultasi bisnis. Keberhasilan PPK FKIP yaitu membina 20 tenant setiap tahun yang terdiri dari $70 \%$ mahasiswa dan $30 \%$ alumni yang sedang menjalankan usaha. Wirausaha baru yang dihasilkan setiap tahun ratarata 5 tenant dengan usaha yang memiliki potensi bisnis dan keunggulan setiap warpen.

\section{Ucapan Terima Kasih}

Tim pelaksana PPK FKIP menyampaikan terima kasih kepada Direktorat Riset dan Pengabdian Masyarakat Kementerian Rieset, Teknologi, dan Pendidikan Tinggi yang telah memberikan hibah pengabdian kepada masyarakat skema Program Pengembangan Kewirausahaan. Ucapan terima kasih juga disampaikan kepada Rektor UNCP yang telah memberikan dukungan moril dan materil.

\section{Referensi}

Adhawati, S. S., Fakhriyah, S., \& Suwarni, S. 2019. Program Pengembangan Usaha 
Produk Intelektual Kampus (PPMU-PPUPIK): Produk Tuna Nut Cookies. Jurnal Panrita Abdi, 3(1), 61-69.

Badan Pusat Statistik (BPS) diakses dari http://www.bps.go.id/, diakses pada tanggal 11 September 2019.

Gorman, G., Hanlon, D., \& King, W. (1997). Entrepreneurship education: the Australian perspective for the nineties. Journal of Small Business Education 9: $1-14$.

Hadiyati, E. (2010). Kajian Pendekatan Pemasaran Kewirausahaan dan Kinerja Penjualan Usaha Kecil. Jurnal Manajemen dan kewirausahaan, 11(2), 183192.

Honig, B., \& Karlsson, T. (2004). Institutional forces and the written business plan. Journal of management, 30(1), 29-48.

Hills, G. E., Hultman, C. M., \& Miles, M. P. (2008). The Evaluation and Development of Entrepreneurial Marketing. Journl of Small Business management, Vol46, Issue 1, P99-112

Kourilsky, M.L. \& Walstad, W.B. (1998). Entrepreneurship and female youth: knowledge, attitude, gender differences, and educational practices". Journal of Business Venturing 13 (1): 77-88.

Indarti, N., \& Rostiani, R. (2008). Intensi kewirausahaan mahasiswa: Studi perbandingan antara Indonesia, Jepang dan Norwegia. Journal of Indonesian Economy and Business, 23(4), 369-384.

Puspitaningtyas, Z. (2017). Manfaat Literasi Keuangan Bagi Business Sustainability. Prosiding Seminar Nasional Kewirausahaan dan Inovasi Bisnis VII (Vol. 7, pp. 252-262). Universitas Tarumanegara.

Rifa'i, M. A., Syahdan, M., Muzdalifah, M., \& Kudsiah, H. (2018). Pengembangan Usaha Produk Intelektual Kampus: Anemon Laut Ornamen. Jurnal Panrita, 2(1), 40-47.

Siswoyo, B. B. (2009). Pengembangan jiwa kewirausahaan di kalangan dosen dan mahasiswa. Jurnal ekonomi bisnis, 14(2), 35-45.

Sutabri, T. (2008). Manajemen Sumber Daya Manusia Indonesia. Yogjakarta : Andi

Wanda M. Widyani. (2013). Pentingnya pola Kemitraan dalam Meningkatkan Peran Kinerja Usaha Mikro, Kecil dan Menengah di Jawa Timur Periode 2006-2011. Universitas Surabaya. Jurnal Calyptra Volume 2 Nomor 2.

Wells, L. E., Farley, H., \& Armstrong, G. A. (2007). The importance of packaging design for own-label food brands. International Journal of Retail \& Distribution Management, 35(9), 677-690.

Penulis:

Ma'rufi, Program Studi Magister Pendidikan Matematika, Fakultas Keguruan dan Ilmu Pendidikan, Universitas Cokroaminoto Palopo, Palopo. E-mail: marufi.ilyas@gmail.com

Muhammad Ilyas, Program Studi Magister Pendidikan Matematika, Fakultas Keguruan dan Ilmu Pendidikan, Universitas Cokroaminoto Palopo, Palopo. E-mail: muhammadilyas949@yahoo.com

Aswar Anas , Program Studi Pendidikan Matematika, Fakultas Keguruan dan Ilmu Pendidikan, Universitas Cokroaminoto Palopo, Palopo. E-mail: aswaranasspd8.com

Reski Yusrini Islamiyah, Program Studi Pendidikan Bahasa Inggris, Fakultas Keguruan dan Ilmu Pendidikan, Universitas Cokroaminoto Palopo, Palopo. E-mail: reski24yunus.ry@gmail.com

Bagaimana men-sitasi artikel ini:

Ma'rufi, Ilyas, M., Anas, A., \& Islamiyah, R.Y. (2020). Pengembangan Kewirausahaan di Fakultas

Keguruan dan Ilmu Pendidikan Universitas Cokroaminoto Palopo. Jurnal Panrita Abdi, 4(2), 225 - 236. 